\title{
An unexpected diagnosis of undetermined biliary stenosis via endoscopic ultrasound
}

Endoscopic diagnosis of indeterminate biliary stenosis is difficult, often requiring repeat examinations [1]. Among rare causes of such stenoses, portal biliopathy is exceptional; $65-85 \%$ of patients with extrahepatic portal obstructions exhibit no symptoms [2,3]. Physiopathologically, the condition is caused by dilation of both plexuses that return the blood of the main bile duct. This develops secondarily to portal hypertension and compresses the common bile duct. Here, we report the case of a 52-year-old patient with a recent history of severe acute pancreatitis complicated by portal thrombosis and infected necrosis drained via a lumen-apposing metal stent. During follow-up several months later, he exhibited cholestasis in hepatic testing, and computed tomography and magnetic resonance imaging revealed dilation of the main biliary tract but no visible obstacle, as well as a possible distal stricture ( Fig.1). Endoscopic ultrasound revealed a dilated main bile duct with a thickened and edematous wall, which was most noticeable at the level of the papilla, suggestive of an inflammatory or tumor cause ( $>$ Fig. 2). Doppler ultrasound showed that the hypoechogenic thickening was attributable to main bile duct hypervascularization ( Fig.3). Transduodenal endoscopic ultrasound revealed several dilated vessels compressing the lower bile duct ( $\triangleright$ Video 1 ). Endoscopic management of such stenoses is associated with a very high risk of hemorrhage [4], especially in patients who have undergone sphincterotomy. We placed a portosystemic shunt in this patient.

Endoscopy_UCTN_Code_CCL_1AZ_2AN
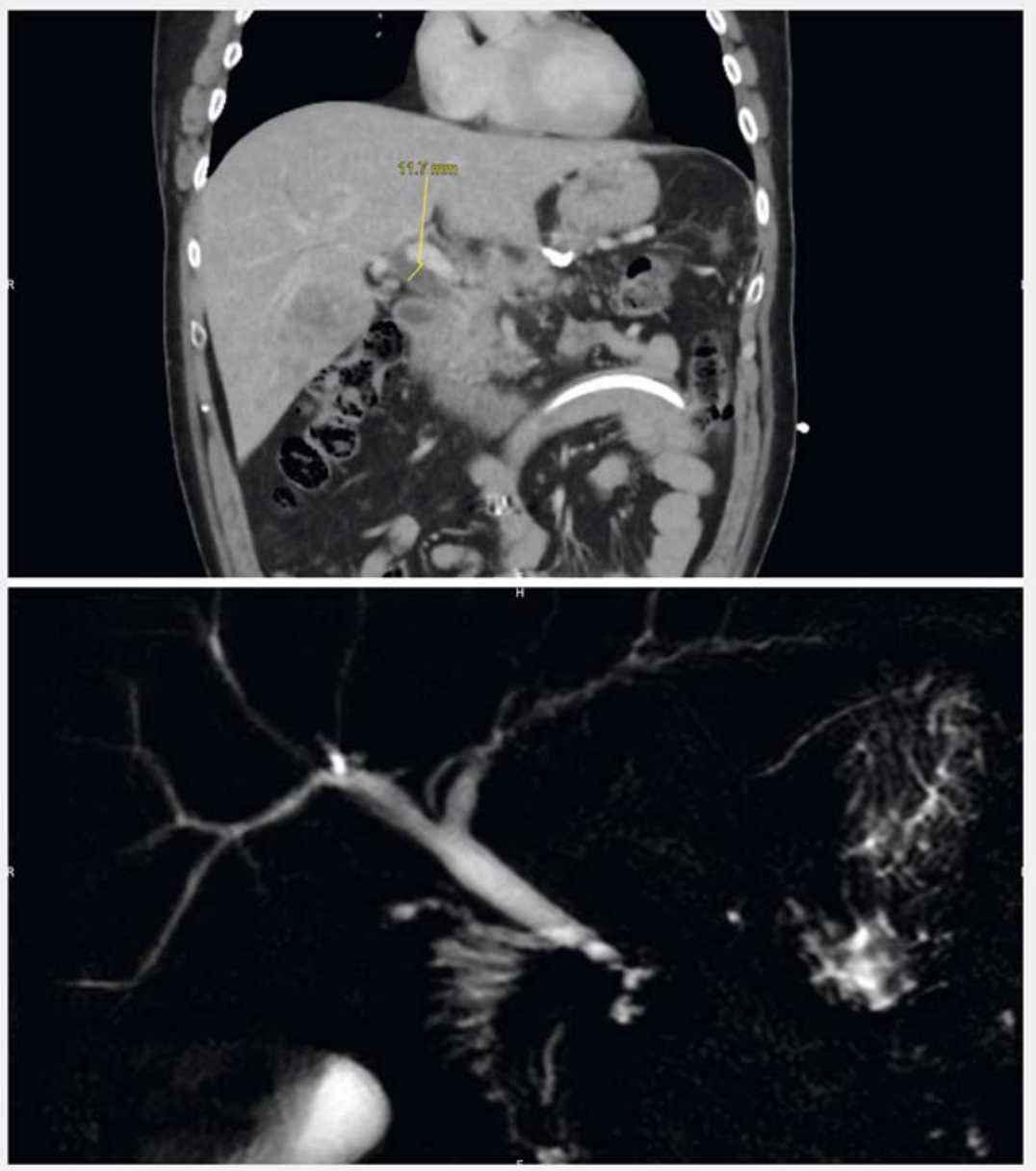

Fig. 1 Computed tomographic scan and magnetic resonance imaging of biliary tract.

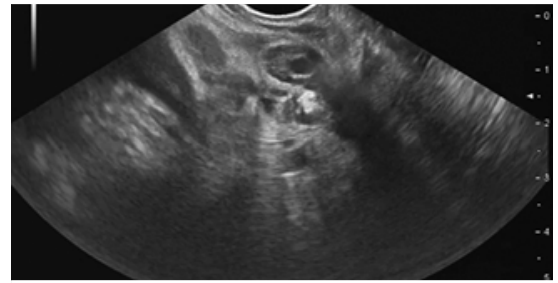

- Fig. 2 Bile duct thickening.

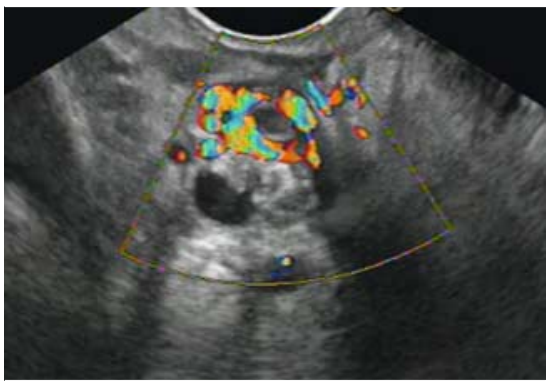

- Fig. 3 Bile duct hypervascularization. 


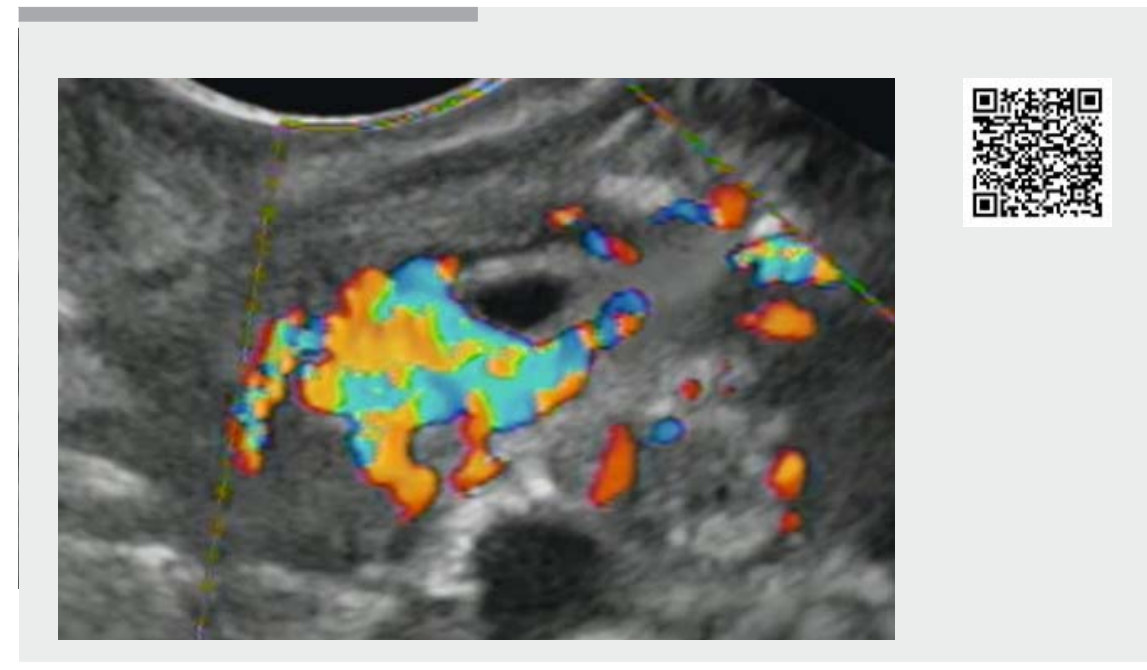

$\checkmark$ Video 1 An unexpected diagnosis when endoscopic ultrasound was used to explore a case of undetermined biliary stenosis.

\section{Competing interests}

Mathieu Pioche: scientific consultant for Olympus, Boston and 3D matrix, ESD training with Cook and Olympus. Véronique Loustaud-Ratti: advisory board and speaking for Gilead and Abbvie. Sophie Geyl: speaking for Abbvie and Ipsen, invitation (conference) for Amgen. Jérémie Jacques and Romain Legros: scientific consultant for Boston and Olympus.

The authors

Jérémie Albouys ${ }^{1}$, Sophie Geyl ${ }^{1}$, Rebecca Rodrigues ${ }^{1}$, Véronique Loustaud-Ratti ${ }^{1}$, Romain Legros ${ }^{1}$, Mathieu Pioche ${ }^{2}$, Jérémie Jacques ${ }^{1}$

1 Gastroentérologie et endoscopie digestive, CHU Dupuytren, Limoges, France

2 Unité d'endoscopie digestive, service de Gastroentérologie - Pavillon H, Hôpital Edouard Herriot, Hospices Civils de Lyon, Lyon, France

\section{Bibliography}

Endoscopy 2021; 53: E31-E32

DOI 10.1055/a-1173-8067

ISSN 0013-726X

published online 29.5.2020

(c) 2020. Thieme. All rights reserved.

Georg Thieme Verlag KG, Rüdigerstraße 14,

70469 Stuttgart, Germany

\section{ENDOSCOPY E-VIDEOS \\ https://eref.thieme.de/e-videos}

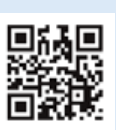

Endoscopy E-Videos is a free access online section, reporting on interesting cases and new

techniques in gastroenterological endoscopy. All papers include a high quality video and all contributions are freely accessible online.

This section has its own submission website at

\section{Jérémie Albouys, MD}

Service d'Hépato-gastroentérologie, $\mathrm{CHU}$ Dupuytren 87042, Limoges, France

Fax: +33-5-55058733

jeremie.albouys@gmail.com

\section{References}

[1] Novikov A, Kowalski TE, Loren DE. Practical management of indeterminate biliary strictures. Gastrointest Endosc Clin N Am 2019; 29: 205-214

[2] Dhiman RK, Behera A, Chawla YK et al. Portal hypertensive biliopathy. Gut 2007; 56: 1001-1008

[3] Chaudhary A, Dhar P, Sarin SK et al. Bile duct obstruction due to portal biliopathy in extrahepatic portal hypertension: surgical management. Br J Surg 1998; 85: 326-329

[4] Dumortier J, Vaillant E, Boillot O et al. Diagnosis and treatment of biliary obstruction caused by portal cavernoma. Endoscopy 2003; 35: 446-450 